\title{
VEGF receptor expression decreases during lung development in congenital diaphragmatic hernia induced by nitrofen
}

\author{
L. Sbragia ${ }^{1}$, A.C.C. Nassr $^{2}$, F.L.L. Gonçalves ${ }^{1}$, A.F. Schmidt ${ }^{3}$, C.C. Zuliani ${ }^{4}$, P.V. Garcia ${ }^{5}$, \\ R.M. Gallindo ${ }^{1}$ and L.A.V. Pereira ${ }^{5}$ \\ ${ }^{1}$ Divisão de Cirurgia Pediátrica, Departamento de Cirurgia e Anatomia, Faculdade de Medicina de Ribeirão Preto, \\ Universidade de São Paulo, Ribeirão Preto, SP, Brasil \\ ${ }^{2}$ Departamento de Hidrobiologia do Centro de Ciências Biológicas e da Saúde, \\ Universidade Federal de São Carlos, São Carlos, SP, Brasil \\ ${ }^{3}$ Pediatrics House Office, Cincinnati Children's Hospital Medical Center, Cincinnati, OH, USA \\ ${ }^{4}$ Departamento de Clínica Médica, Faculdade de Ciências Médicas, \\ Universidade Estadual de Campinas, Campinas, SP, Brasil \\ ${ }^{5}$ Departamento de Histologia e Embriologia, Instituto de Biologia, \\ Universidade Estadual de Campinas, UNICAMP, Campinas, SP, Brasil
}

\begin{abstract}
Changes in vascular endothelial growth factor (VEGF) in pulmonary vessels have been described in congenital diaphragmatic hernia $(\mathrm{CDH})$ and may contribute to the development of pulmonary hypoplasia and hypertension; however, how the expression of VEGF receptors changes during fetal lung development in $\mathrm{CDH}$ is not understood. The aim of this study was to compare morphological evolution with expression of VEGF receptors, VEGFR1 (FIt-1) and VEGFR2 (FIk-1), in pseudoglandular, canalicular, and saccular stages of lung development in normal rat fetuses and in fetuses with $\mathrm{CDH}$. Pregnant rats were divided into four groups ( $n=20$ fetuses each) of four different gestational days (GD) 18.5, 19.5, 20.5, 21.5: external control (EC), exposed to olive oil (OO), exposed to $100 \mathrm{mg}$ nitrofen, by gavage, without $\mathrm{CDH}(\mathrm{N}-$ ), and exposed to nitrofen with $\mathrm{CDH}$ (CDH) on GD 9.5 (term = 22 days). The morphological variables studied were: body weight $(B W)$, total lung weight (TLW), left lung weight, TLW/BW ratio, total lung volume, and left lung volume. The histometric variables studied were: left lung parenchymal area density and left lung parenchymal volume. VEGFR1 and VEGFR2 expression were determined by Western blotting. The data were analyzed using analysis of variance with the Tukey-Kramer post hoc test. CDH frequency was 37\% (80/216). All the morphological and histometric variables were reduced in the $\mathrm{N}$ - and $\mathrm{CDH}$ groups compared with the controls, and reductions were more pronounced in the CDH group $(P<0.05)$ and more evident on GD 20.5 and GD 21.5. Similar results were observed for VEGFR1 and VEGFR2 expression. We conclude that $\mathrm{N}$ - and CDH fetuses showed primary pulmonary hypoplasia, with a decrease in VEGFR1 and VEGFR2 expression.
\end{abstract}

Key words: Congenital diaphragmatic hernia; VEGFR; Rat model; Nitrofen; Lung development

\section{Introduction}

Congenital diaphragmatic hernia $(\mathrm{CDH})$ occurs in approximately 1 in 2500 live births and still causes high neonatal mortality as a consequence of pulmonary hypoplasia and persistent pulmonary hypertension (1). Vascular endothelial growth factor (VEGF) and its receptors, VEGFR1 (FIt-1) and VEGFR2 (FIk-1), participate in angiogenesis by stimulating proliferation of new vessels and by offering a background for airway branching $(2,3)$.
VEGFR2 signaling produces various cellular responses, including mitogenic and survival signals for endothelial cells and their precursors $(4,5)$, therefore silencing the VEGFR2 gene reduces or suppresses of vasculogenesis in rats $(6,7)$. VEGFR1 participates in the development of blood vessels by negatively modulating endothelial cell division through a restriction of VEGFR2 signaling $(8,9)$. Knockout mice for the VEGFR1 gene did

Correspondence: L. Sbragia, Divisão de Cirurgia Pediátrica, Departamento de Cirurgia e Anatomia, Faculdade de Medicina de Ribeirao Preto, USP, Av. Bandeirantes, 3900, 14049-900 Ribeirão Preto, SP, Brasil. Fax: +55-16-3633-0836. E-mail: sbragia@fmrp.usp.br 
not survive to the end of pregnancy due to hypertrophy and disorganization of the vascular bed (10).

The changes in pulmonary vessels and serum levels of VEGF described in CDH likely contribute to the development of pulmonary hypoplasia and hypertension (11). VEGF participates in pulmonary development and surfactant production and induces conversion of glycogen into surfactant in type II pneumocytes (12); however, there are a limited number of studies on VEGF receptors. Changes in the levels of VEGF and its receptors cause a disturbance in angiogenesis, leading to a detrimental remodeling of small arteries. Studies of the expression of VEGF in $\mathrm{CDH}$ have produced conflicting results.

One study showed that VEGF increased in the nitrofen-induced $\mathrm{CDH}$ rat model with pulmonary hypertension; however, several other studies showed that VEGF decreased in the same model $(13,14)$. Considering that not only VEGF but also the VEGF receptors may be involved in the development of pulmonary hypertension, our aim was to examine the expression of these receptors in the pseudoglandular, canalicular, and saccular stages of lung development of normal rat fetuses and of fetuses with $\mathrm{CDH}$.

\section{Material and Methods}

Experimental protocols were reviewed and approved by the Animal Experimentation Committee of the Faculdade de Medicina de Ribeirão Preto, Universidade de São Paulo (FMRP-USP; \#043/2011).

Sprague-Dawley rats $( \pm 250 \mathrm{~g})$ were mated during the night cycle and females were checked on the following day for a sperm-positive vaginal smear. The day of plugging was defined as gestational day 0 (term $=22$ days). A total of 52 pregnant rats were studied in four groups: 10 external control (EC), 10 exposed to olive oil (OO), and 32 rats exposed to nitrofen that did not develop $\mathrm{CDH}(\mathrm{N}-)$ or that did develop $\mathrm{CDH}(\mathrm{CDH})$.

\section{Nitrofen administration}

To induce $\mathrm{CDH}$, timed-pregnant rats were given $100 \mathrm{mg}$ nitrofen (2,4-dichloro-4-nitrodiphenyl ether, Maybridge ${ }^{\mathbb{R}}$; UK) dissolved in $1 \mathrm{~mL}$ olive oil on gestational day (GD) 9.5 , by gavage. The placebo group received $1 \mathrm{~mL}$ olive oil without nitrofen at the same gestational age (OO group). This dose of nitrofen has been shown to cause left-sided $\mathrm{CDH}$ in $24 \%$ of the litter (15).

\section{Model and experimental groups}

All four groups of fetuses (EC, OO, $\mathrm{N}$-, and $\mathrm{CDH}$ ) were harvested at $18.5,19.5,20.5$, or $21.5 \mathrm{GD}$ (20 fetuses per group for each gestational day, giving a total of 80 fetuses in each group). The pregnant female rats were anesthetized on the specific day of gestation using $50 \mathrm{mg} / \mathrm{mL}$ ketamine $\left(175 \mathrm{mg} / \mathrm{kg}\right.$; Ketamina ${ }^{\circledR}$, Pfizer do Brasil Ltda., Brazil) in conjunction with $10 \mathrm{mg} / \mathrm{mL}$ xylazine $(2.5 \mathrm{mg} / \mathrm{kg}$;
Rompum $^{\circledR}$, Bayer do Brasil Ltda., Brazil), and the fetuses were collected through a median maternal laparotomy and hysterotomy.

\section{Morphological measurements}

The fetuses were weighed [body weight (BW)] and dissected. Their left lung weight (LLW) and total lung weight (TLW) were measured, and the lung-to-body weight ratio (TLW/BW) was determined as were the total lung volume [V(lu)], left lung volume [V(llu)], left lung parenchymal area density $\left[A_{A}(p a / l l u)\right]$, and left lung parenchymal volume $[\mathrm{V}(\mathrm{pal})]$.

\section{Histological analysis}

The left lungs were fixed, washed in phosphate buffer, and processed following a protocol for paraffin embedding. The histological samples were sectioned $(5 \mu \mathrm{m}$ thick), and sections were deparaffinized and stained with hematoxylin-eosin, and examined by light microscopy.

\section{Obtaining images for analysis}

Images from the histological sections of the left lung were obtained at $200 \times$ magnification. We analyzed 50 images per animal, from five animals per group in each endpoint, totaling 200 images for each group. For stereological analysis, we used a grid with 100 points generated by the Image-Pro Plus software, version 4.1.0.0 (Media Cybernetics, USA).

\section{Stereological calculations}

Lung volume [V(lu)]. The total V(lu) was calculated using Archimedes' principle. The volume of the lung was determined from the volume of water displaced when it was suspended by a wire in a container of water (and not touching the walls or bottom of the container), as described by Scherle (16) and Howard and Reed (17).

Volume of parenchyma $[V(p a)]$. The density of the parenchymal area $\left[\mathrm{A}_{\mathrm{A}}(\mathrm{pa} / \mathrm{lu})\right]$ was estimated by dividing the number of points that fall in the pa, excluding large bronchi and large blood vessels, by the number of points that fall within the lung as a whole (lu), excluding the airspace, at $200 \times$ magnification $\left[A_{A}(p a / l u)=p a / l u\right]$. The volume of the left lung parenchyma $[\mathrm{V}(\mathrm{pal})]$ was obtained by multiplying the left lung volume $[\mathrm{V}(\mathrm{Ilu})]$ by the $\mathrm{A}_{\mathrm{A}}(\mathrm{pa} /$ $\mathrm{llu}$ ), according to Papadakis et al. (18) $[\mathrm{V}(\mathrm{pal})=\mathrm{V}(\mathrm{llu})$ $\times A_{A}(p a / l l u)$, utilizing the Image Pro Plus 6.0 software (Media Cybernetics).

\section{Western blotting}

Whole lungs from 6 animals per group were homogenized in $1 \mathrm{~mL}$ extraction buffer containing $100 \mathrm{mM}$ Tris, $\mathrm{pH}$ 7.4, $100 \mathrm{mM}$ sodium pyrophosphate, $100 \mathrm{mM}$ sodium fluoride, $10 \mathrm{mM}$ EDTA, $10 \mathrm{mM}$ sodium vanadate, $2 \mathrm{mM}$ phenylmethylsulfonyl fluoride, $0.1 \mathrm{mg} / \mathrm{mL}$ aprotinin, and $1 \%$ Triton- $X 100$ at $4{ }^{\circ} \mathrm{C}$ with a tissue homogenizer (Tecnal, Brazil) operated at maximum speed for $30 \mathrm{~s}$. The extracts 
Table 1. Morphological variables of fetuses.

\begin{tabular}{|c|c|c|c|c|c|c|c|c|}
\hline Group/GD & BW & TLW & LLW & TLW/BW & $\mathrm{V}(\mathrm{lu})$ & $\mathrm{V}(\mathrm{llu})$ & $A_{A}(p a / l l u)$ & $\mathrm{V}(\mathrm{pal})$ \\
\hline \multicolumn{9}{|l|}{ EC } \\
\hline 18.5 & $237 \pm 19$ & $80 \pm 17$ & $29 \pm 6$ & $0.034 \pm 0.006$ & $78 \pm 16$ & $27 \pm 6$ & $0.77 \pm 0.05$ & $2074 \pm 132$ \\
\hline 19.5 & $391 \pm 40$ & $126 \pm 11$ & $43 \pm 6$ & $0.033 \pm 0.003$ & $123 \pm 11$ & $41 \pm 6$ & $0.66 \pm 0.06$ & $2709 \pm 265$ \\
\hline 20.5 & $555 \pm 41$ & $147 \pm 33$ & $51 \pm 11$ & $0.027 \pm 0.007$ & $143 \pm 34$ & $49 \pm 13$ & $0.63 \pm 0.06$ & $3132 \pm 285$ \\
\hline 21.5 & $647 \pm 48$ & $145 \pm 17$ & $50 \pm 7$ & $0.023 \pm 0.003$ & $143 \pm 16$ & $48 \pm 6$ & $0.49 \pm 0.10$ & $2348 \pm 490$ \\
\hline \multicolumn{9}{|l|}{$\mathrm{OO}$} \\
\hline 18.5 & $244 \pm 13$ & $89 \pm 9$ & $29 \pm 3$ & $0.037 \pm 0.003$ & $86 \pm 10$ & $28 \pm 3$ & $0.88 \pm 0.06^{\mathrm{ac}}$ & $2454 \pm 175^{\mathrm{ac}}$ \\
\hline 19.5 & $364 \pm 32^{\mathrm{a}}$ & $130 \pm 17$ & $44 \pm 6$ & $0.036 \pm 0.003^{\mathrm{a}}$ & $127 \pm 17$ & $40 \pm 11$ & $0.75 \pm 0.05^{\mathrm{ac}}$ & $3072 \pm 203^{\mathrm{ac}}$ \\
\hline 20.5 & $503 \pm 43^{a}$ & $140 \pm 15$ & $48 \pm 6$ & $0.028 \pm 0.003$ & $137 \pm 15$ & $46 \pm 6$ & $0.63 \pm 0.05^{\mathrm{c}}$ & $2906 \pm 250^{\mathrm{ac}}$ \\
\hline 21.5 & $580 \pm 29^{a}$ & $144 \pm 12$ & $49 \pm 5$ & $0.025 \pm 0.002^{\mathrm{a}}$ & $140 \pm 12$ & $47 \pm 5$ & $0.58 \pm 0.07^{\mathrm{ac}}$ & $2704 \pm 314^{a}$ \\
\hline \multicolumn{9}{|c|}{ 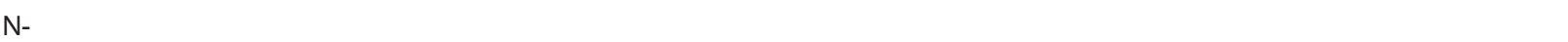 } \\
\hline 18.5 & $211 \pm 17^{\mathrm{ab}}$ & $63 \pm 11^{\mathrm{ab}}$ & $23 \pm 4^{\mathrm{ab}}$ & $0.030 \pm 0.004^{\mathrm{ab}}$ & $59 \pm 10^{a b}$ & $21 \pm 4^{\mathrm{ab}}$ & $0.80 \pm 0.05^{\mathrm{ab}}$ & $1671 \pm 104^{\mathrm{ab}}$ \\
\hline 19.5 & $342 \pm 20^{\mathrm{a}}$ & $105 \pm 15^{\mathrm{ab}}$ & $38 \pm 5^{\mathrm{ab}}$ & $0.030 \pm 0.004^{\mathrm{ab}}$ & $101 \pm 15^{\mathrm{ab}}$ & $36 \pm 6$ & $0.67 \pm 0.05^{\mathrm{b}}$ & $2432 \pm 197^{a}$ \\
\hline 20.5 & $457 \pm 39^{a b}$ & $104 \pm 16^{\mathrm{ab}}$ & $38 \pm 7^{\mathrm{ab}}$ & $0.023 \pm 0.003^{\mathrm{ab}}$ & $100 \pm 16^{\mathrm{ab}}$ & $36 \pm 6^{a b}$ & $0.53 \pm 0.06^{\mathrm{ab}}$ & $2416 \pm 195^{\mathrm{ab}}$ \\
\hline 21.5 & $561 \pm 55$ & $101 \pm 19^{a b}$ & $38 \pm 6^{a b}$ & $0.018 \pm 0.003^{\mathrm{ab}}$ & $97 \pm 19^{a b}$ & $36 \pm 6^{a b}$ & $0.55 \pm 0.10^{\mathrm{b}}$ & $2091 \pm 261^{\mathrm{b}}$ \\
\hline \multicolumn{9}{|l|}{$\mathrm{CDH}$} \\
\hline 18.5 & $213 \pm 20^{\mathrm{ab}}$ & $59 \pm 8^{\mathrm{ab}}$ & $20 \pm 3^{a b}$ & $0.028 \pm 0.005^{\mathrm{ab}}$ & $56 \pm 8^{a b c}$ & $19 \pm 3^{a b}$ & $0.85 \pm 0.05^{\mathrm{ac}}$ & $1615 \pm 86^{\mathrm{ac}}$ \\
\hline 19.5 & $310 \pm 25^{a b c}$ & $77 \pm 14^{\mathrm{abc}}$ & $25 \pm 6^{\mathrm{abc}}$ & $0.024 \pm 0.001^{a b c}$ & $74 \pm 15^{\mathrm{abc}}$ & $24 \pm 7^{a b c}$ & $0.80 \pm 0.05^{a b c}$ & $1925 \pm 118^{\mathrm{abc}}$ \\
\hline 20.5 & $451 \pm 36^{a b}$ & $80 \pm 12^{\mathrm{abc}}$ & $25 \pm 5^{\mathrm{abc}}$ & $0.018 \pm 0.002^{a b c}$ & $76 \pm 12^{a b c}$ & $23 \pm 6^{a b c}$ & $0.80 \pm 0.05^{a b c}$ & $1928 \pm 125^{a b c}$ \\
\hline 21.5 & $541 \pm 51$ & $78 \pm 13^{\mathrm{abc}}$ & $25 \pm 6^{a b c}$ & $0.014 \pm 0.002^{\mathrm{abc}}$ & $76 \pm 14^{a b c}$ & $23 \pm 5^{a b c}$ & $0.78 \pm 0.05^{\mathrm{ac}}$ & $1804 \pm 113^{\mathrm{abc}}$ \\
\hline
\end{tabular}

Data are reported as means \pm SD. GD: gestational days; BW: body weight; TLW: total lung weight; LLW: left lung weight; TLW/BW: TLW/BW ratio; $V(\mathrm{lu})$ : total lung volume; $\mathrm{V}(\mathrm{llu})$ : left lung volume; $\mathrm{A}_{\mathrm{A}}(\mathrm{pa} / \mathrm{lu})$ : left lung parenchymal area density; $\mathrm{V}(\mathrm{pal})$ : left lung parenchymal volume; EC: external controls; OO: exposed to olive oil; $\mathrm{N}$-: exposed to nitrofen without $\mathrm{CDH}$; $\mathrm{CDH}$ : exposed to nitrofen with $\mathrm{CDH}$; ${ }^{\text {a }} \mathrm{P}<0.05$ compared with $\mathrm{EC}$ group; ${ }^{\mathrm{b}} \mathrm{P}<0.05$ compared with $\mathrm{OO}$ group; ${ }^{\mathrm{C}} \mathrm{P}<0.05$ compared with $\mathrm{N}$ - group.

were centrifuged at $9000 \mathrm{~g}$ at $4^{\circ} \mathrm{C}$ in a Mikro 200R centrifuge (Hettich, Germany) for $30 \mathrm{~min}$ to remove insoluble material, and the supernatants of these tissues were used for protein quantification using the Bradford method. Then, $90 \mu \mathrm{g}$ protein was denatured, run on SDSPAGE, and transferred to nitrocellulose membranes in two stages for $1 \mathrm{~h}$ each at $120 \mathrm{~V}$. The membranes were blocked for $1 \mathrm{~h}$ in $5 \%$ milk in $0.01 \mathrm{M} \mathrm{PBS}, \mathrm{pH} 7.4$, and incubated with anti-VEGFR1 (sc-316, Santa Cruz Biotechnology, USA) or anti-VEGFR2 (sc-6251, Santa Cruz Biotechnology) diluted $1: 200$ in 5\% milk in $0.01 \mathrm{M}$ PBS, pH 7.4, for $2 \mathrm{~h}$ at room temperature. They were then incubated with biotin-conjugated anti-rabbit IgG (1:10,000 in $1 \% \mathrm{BSA}$ ) for $2 \mathrm{~h}$ at room temperature for VEGFR1 and with biotin-conjugated anti-mouse $\lg$ (1:5000 in 1\% BSA) for $2 \mathrm{~h}$ for VEGFR2. Finally, the membranes were probed with the Supersignal Chemiluminescence kit (Pierce, USA), exposed to radiographic films for $7 \mathrm{~min}$ (Kodak, USA), and developed.

\section{Statistical analysis}

Morphological data were compared by analysis of variance and by the Tukey-Kramer post hoc test using the Statistical Analysis System for Windows (SAS 8.01, SAS Institute, USA). Statistical significance was considered to be $\mathrm{P}<0.05$.

\section{Results}

\section{Morphological}

Examination of the nitrofen-exposed fetuses showed that $37 \%(80 / 216)$ had $\mathrm{CDH}$. All the morphological and histometric variables showed reductions in the $\mathrm{N}$ - and $\mathrm{CDH}$ groups, compared with the controls (EC and OO groups), which were more pronounced in those with $\mathrm{CDH}$ ). All fetuses exposed to nitrofen ( $\mathrm{N}$ - and $\mathrm{CDH}$ groups) had decreased BW, TLW, LLW, TLW/BW, V(lu), V(llu), A $($ pa/llu), and V(pal) compared with non-exposed fetuses (EC and OO groups, $\mathrm{P}<0.05)$. Fetuses with $\mathrm{CDH}$ showed decreased TLW, LLW, TLW/BW, V(lu), V(llu), $A_{A}(p a / l l u)$, and V(pal) compared with $\mathrm{N}$ - fetuses at GD 19.5, 20.5, and $21.5(\mathrm{P}<0.001)$, but there was no difference at GD 18.5 (see Table 1 and Figure 1).

\section{Histology}

On GD 18.5, 19.5, 20.5, and 21.5, the development of an airspace in the $\mathrm{EC}, \mathrm{OO}$, and $\mathrm{N}$ - groups was observed. However, the opposite occurred in the $\mathrm{CDH}$ group, with decreased airspace and pulmonary hypoplasia increasingly evident at the later gestational ages (Figure 2).

\section{Western blotting}

Our results demonstrated that the protein expression levels of VEGFR1 and VEGFR2 in these four development 
A

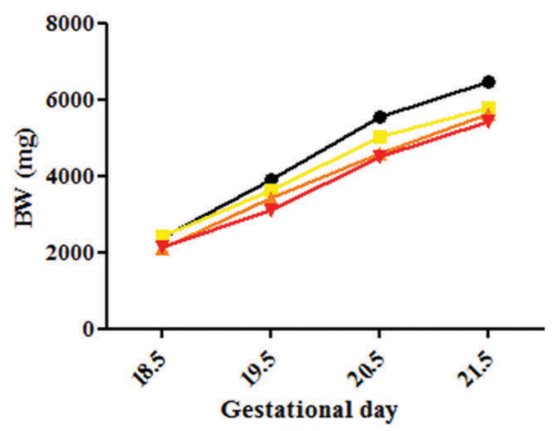

B

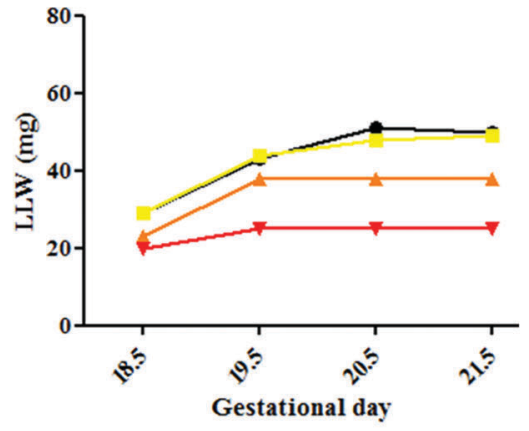

C

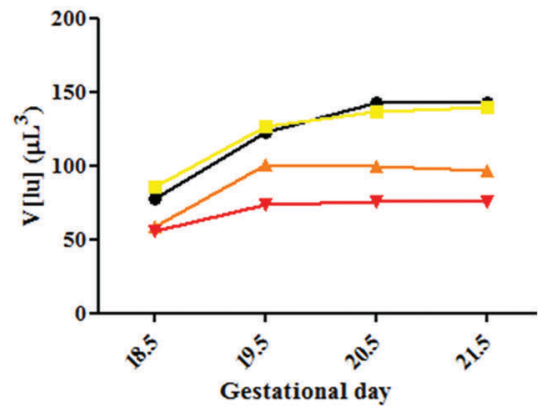

D

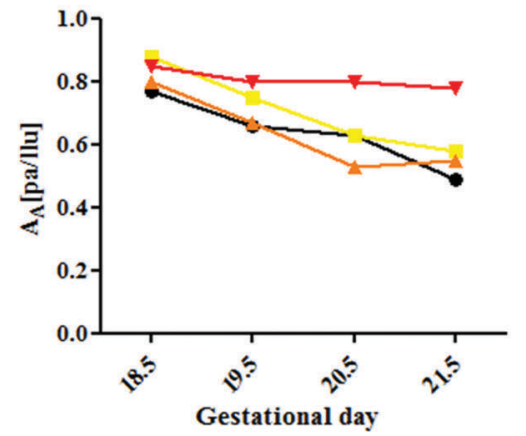

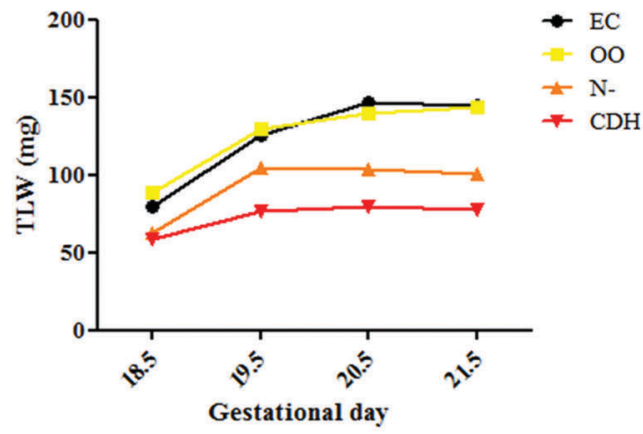
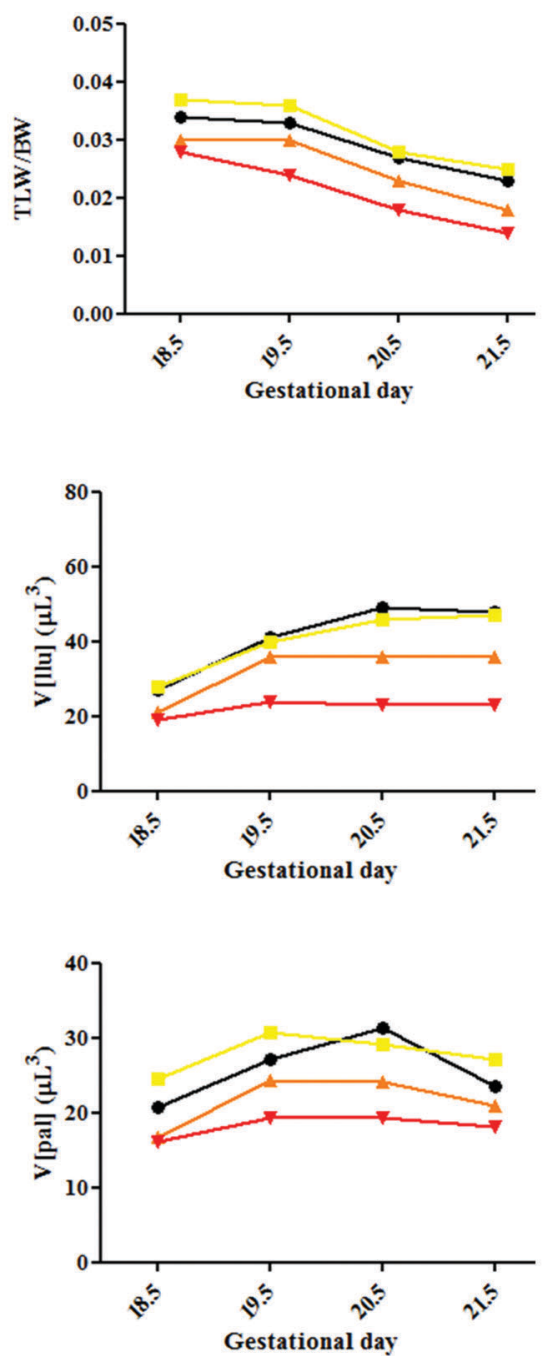

Figure 1. Evolution at $18.5,19.5,20.5$, and 21.5 gestational days of: $A$, body weight (BW) and total lung weight (TLW); $B$, left lung weight (LLW) and TLW/BW ratio; $C$, total lung volume [V(lu)] and left lung volume [V(llu)]; $D$, left lung parenchymal area density $\left[\mathrm{A}_{\mathrm{A}}(\mathrm{pa} /\right.$ $\mathrm{llu})]$ and left lung parenchyma volume [V(pal)]. EC: external control; OO: exposed to olive oil; $\mathrm{N}$-: exposed to nitrofen without $\mathrm{CDH}$; $\mathrm{CDH}$ : exposed to nitrofen with $\mathrm{CDH}$. 


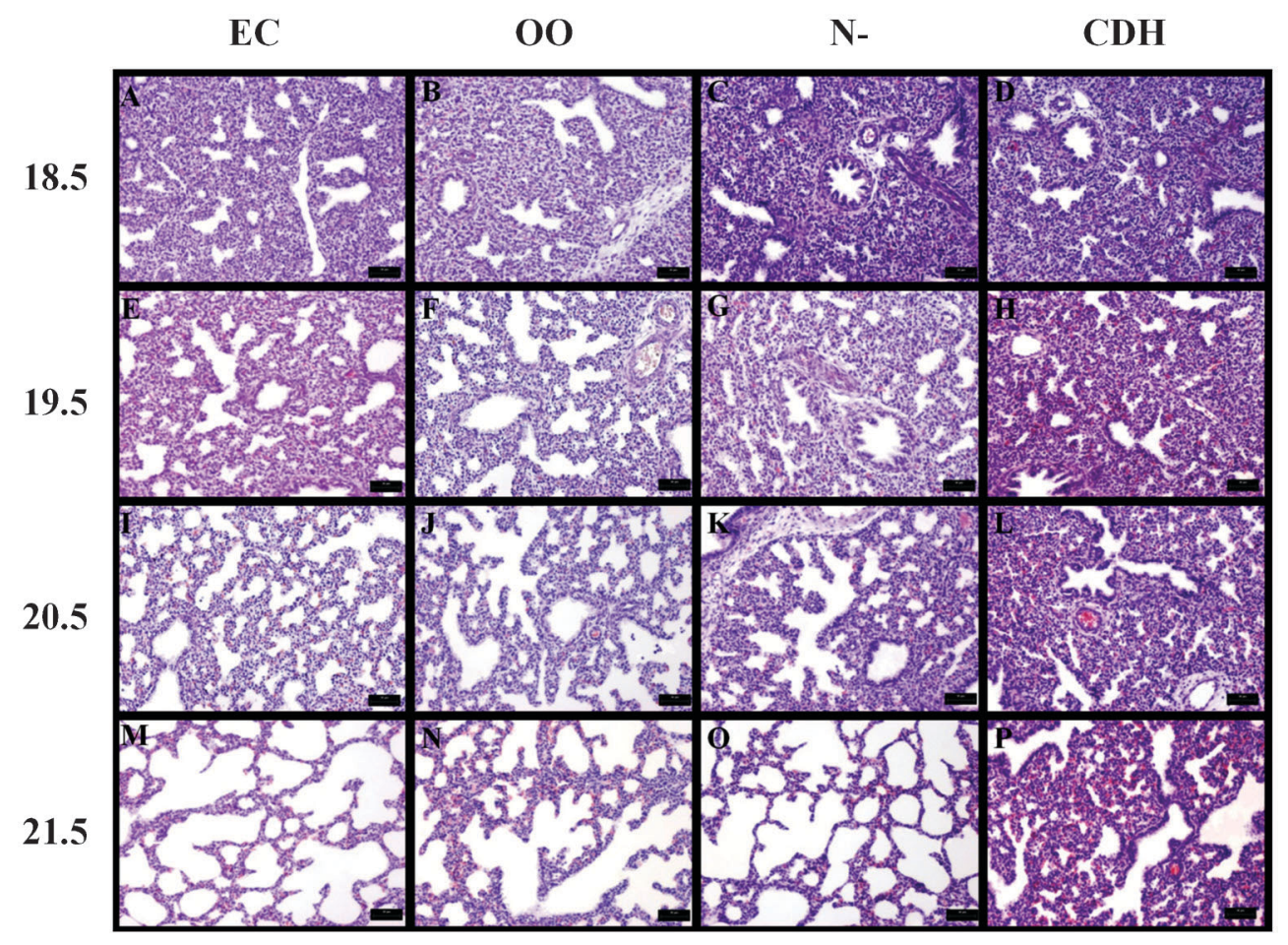

Figure 2. Photomicrographs of fetal lungs from the external control (EC), exposed to olive oil (OO), exposed to nitrofen without $\mathrm{CDH}$ $(\mathrm{N}-)$, and exposed to nitrofen with congenital diaphragmatic hernia $(\mathrm{CDH})$ groups at gestational days $18.5,19.5,20.5$, and 21.5 . There was a decrease in the airspace in panels $H, L$, and $P$, demonstrating pulmonary hypoplasia in the $\mathrm{CDH}$ group at later gestational ages. H\&E staining, bars: $50 \mu \mathrm{m}$.

phases were lower in the $\mathrm{CDH}$ group than in the $\mathrm{N}-, \mathrm{EC}$, and $\mathrm{OO}$ groups $(\mathrm{P}<0.001$; see Figure 3$)$.

\section{Discussion}

The rat model of CDH pioneered by Iritani (19) allowed reproduction of all components of the malformation by administration of nitrofen (2,4-dichloro-4'-nitrodiphenyl ether) to pregnant rats during the appropriate embryologic window. The nature of lung hypoplasia associated with $\mathrm{CDH}$ has been investigated in this model, and a dual-hit mechanism involving primary maldevelopment and secondary compressive changes is currently accepted (2022).

Although we did not address the early (embryonic) stage of lung development, our results are consistent with those of Kluth et al. (15) in terms of the proportion of $\mathrm{CDH}$ in exposed fetuses (37 vs 24\%) and with those of Pringle (23) in terms of the timing of the pseudoglandular (GD 18.5), canalicular (GD 18.5, 19.5 and 20.5), and saccular (GD 20.5 and 21.5) stages of lung development.

We found that BW, TLW, LLW, V(lu), and V(llu) increased progressively during fetal development, whereas TLW/BW decreased in all groups, particularly in those with $\mathrm{CDH}(\mathrm{P}<0.001)$, in agreement with previous reports (22). Recently, we published two studies that showed similar results in BW, TLW and LLW, but we have not calculated the lung volume at 21.5 days $(24,25)$. The $\mathrm{V}$ (pal) in fetuses exposed to nitrofen was smaller than for those in the EC and $\mathrm{OO}$ groups, indicating that the primary lung injury caused by nitrofen occurred early, evidenced by similar $\mathrm{V}$ (pal) in $\mathrm{N}$ - and $\mathrm{CDH}$ groups. The $\mathrm{V}(\mathrm{Ilu})$ and the LLW were also similar in the two groups exposed to nitrofen, possibly due to impaired airspace development because of the intrathoracic presence of abdominal organs. This is more evident in fetuses with $\mathrm{CDH}$ in comparison to all other groups $(\mathrm{P}<0.05)$.

We observed that the $\mathrm{EC}$ and $\mathrm{OO}$ groups were very similar when comparing variables during the same gestational period. We believe that small differences between these groups may be related to the stress of gavaging olive oil to the pregnant rats, or to the nutritional supply of extra fat because the olive oil is not part of normal diet of these animals. Moreover, none of the authors who used the nitrofen model have shown a comparison with an EC group, perhaps because they believe that the OO group is the only real control.

VEGF is a key stimulator of angiogenesis that acts to induce mitosis and migration of vascular endothelial cells. In addition to promoting angiogenesis and neovascularization, 


\section{VEGFR1}

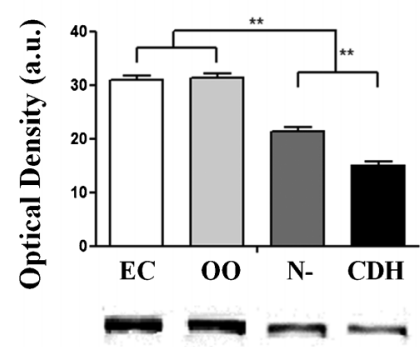

18.5 days

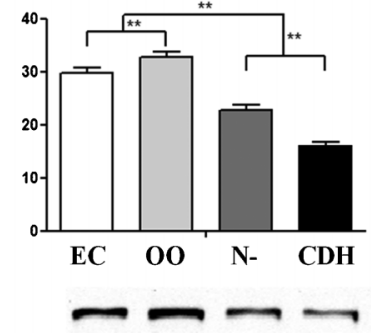

19.5 days

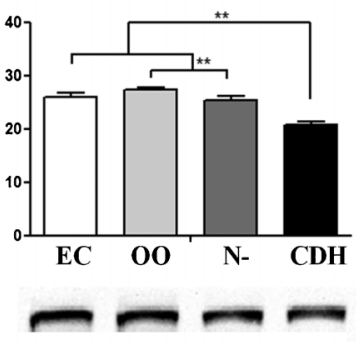

20.5 days

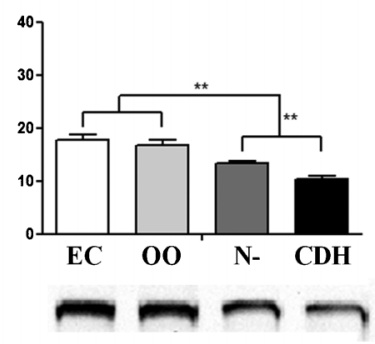

21.5 days

VEGFR2

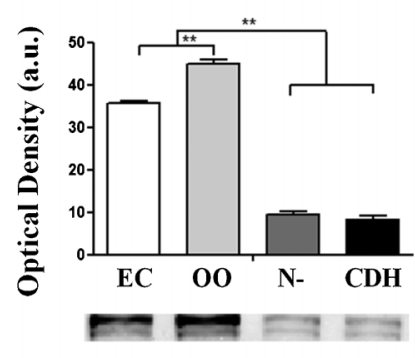

18.5 days

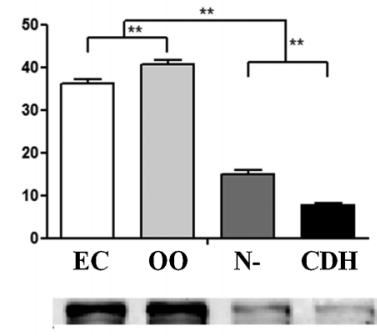

19.5 days

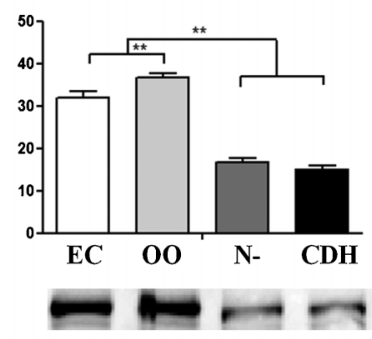

20.5 days

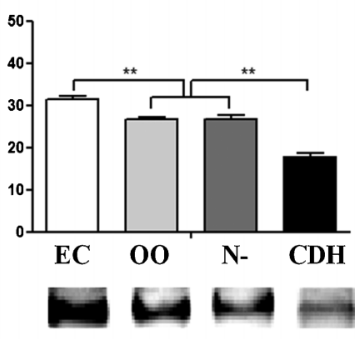

21.5 days

Figure 3. Evolution of vascular endothelial growth factor receptors (VEGFR1 and VEGFR2) at 18.5, 19.5, 20.5, and 21.5 days of gestation. EC: external control; OO: exposed to olive oil; $\mathrm{N}$-: exposed to nitrofen without $\mathrm{CDH}$; $\mathrm{CDH}$ : exposed to nitrofen with $\mathrm{CDH}$. ${ }^{* *} \mathrm{P}<0.001$ (analysis of variance with Tukey-Kramer post hoc test).

it is also a survival factor for newly formed blood vessels (26-28). The vessels' receptors, VEGFR1 (FIt-1) and VEGFR2 (Flk-1) in rats and KDR in humans, have tyrosine kinase activity and function in the opening of $\mathrm{Ca}^{2+}$ channels located in the membranes of endothelial cells (29-31).

Among the various effects of VEGF in vascular and epithelial cells, the temporal-spatial expression of VEGF has been suggested to be important, not only for the formation of capillaries but also for controlling bronchial and alveolar growth (32-34). Changes in VEGF and its receptors cause a disturbance of angiogenesis, leading to a detrimental remodeling of small arteries. Tenbrinck et al. (35) showed that, in $\mathrm{CDH}$, the arterioles on the level of respiratory bronchioles and larger airways had an increased wall thickness (muscularization) that extends into the peripheral pulmonary artery.

The level of VEGF is increased in primary pulmonary hypertension of the newborn (PPHN), but this increase appears to result from hypoxia in lung tissue (due to pulmonary hypertension and lower blood flow) rather than hypertension being due to increased VEGF levels. Thus, the VEGF increase is a consequence of the pulmonary hypertension and not the cause. In this process, a derangement in angiogenesis occurs and the resulting increase in VEGF might compensate for this problem and produce more blood vessels and blood flow, but this mechanism worsens the situation because the vessels are formed in a disorganized fashion (36). Although the mechanism of PPHN is not the same because in $\mathrm{CDH}$ the hypertension is secondary to anatomical changes in the pulmonary vasculature before birth, the reduced flow could lead to a final picture similar to PPHN.

VEGF increased in CDH in just one study (13), and others showed that VEGF decreased in the nitrofen model (14). There is no consensus as to whether VEGF increases or decreases in this model. Shehata et al. (37) found increased VEGF expression in the lungs of newborns with $\mathrm{CDH}$, who died of severe pulmonary hypertension. Oue et al. (38) reported that VEGF increased, but it could not be excluded that this increase resulted from nitrofen's own toxic action. Okazaki et al. (11) found that VEGF expression was reduced in $\mathrm{CDH}$ and suggested that the mechanisms involved in its receptors could contribute to increase pulmonary hypertension in the disease. Chang et al. (14) found decreased 
VEGF, and Hara et al. (39) found, in fetal rats, that VEGF increased in lung tissue after performing a tracheal occlusion. We previously reported that VEGF expression decreased in $\mathrm{CDH}$, but after performing a tracheal occlusion with the use of corticosteroids, VEGF expression increased (24).

Similar to our previous results for VEGF (38), the levels of VEGFR1 and VEGFR2 in pseudoglandular, canalicular, and saccular phases of lung development decreased in the nitrofen group relative to the $\mathrm{EC}$ and $\mathrm{OO}$ groups, with an even lower expression in $\mathrm{CDH}$ fetuses $(\mathrm{P}<0.001)$.

VEGFR2 is expressed in the early stages of lung development, whereas VEGFR1 expression increases in the later stages of development. Thus, it is believed that VEGFR2 affects the activation of angiogenesis, while VEGFR1 functions in the maturation and integrity of the vessel wall. Due to its high affinity for VEGF, but lower tyrosine kinase activity, VEGFR1 has been implicated in the sequestration of VEGF, decreasing its availability to bind VEGFR2, thus acting in the resolution of the angiogenesis phase $(8,40)$. There is a correlation between high levels of VEGF and fetal lung maturation. Hypoxia of lung tissues activates the HIF-2 $\alpha$ gene, inducing the production of VEGF that appears to act on type II pneumocytes through tyrosine kinase receptors (Flt-1 and Flk-1) and increases the production of surfactant.

VEGF-deficient mice exposed to intrauterine antiVEGF receptor (Flk-1) antibodies present respiratory distress syndrome, due to surfactant deficiency. Intrauterine application or intratracheal postnatal instillation of VEGF stimulates surfactant production and may

\section{References}

1. Golombek SG. The history of congenital diaphragmatic hernia from 1850s to the present. J Perinatol 2002; 22: 242246, doi: $10.1038 /$ sj.jp.7210701.

2. van Tuyl M, Liu J, Wang J, Kuliszewski M, Tibboel D, Post M. Role of oxygen and vascular development in epithelial branching morphogenesis of the developing mouse lung. Am J Physiol Lung Cell Mol Physiol 2005; 288: L167-L178, doi: 10.1152/ajplung.00185.2004.

3. Toi M, Matsumoto T, Bando H. Vascular endothelial growth factor: its prognostic, predictive, and therapeutic implications. Lancet Oncol 2001; 2: 667-673, doi: 10.1016/S14702045(01)00556-3.

4. Bernatchez PN, Soker S, Sirois MG. Vascular endothelial growth factor effect on endothelial cell proliferation, migration, and platelet-activating factor synthesis is Flk-1-dependent. J Biol Chem 1999; 274: 31047-31054, doi: 10.1074/jbc.274. 43.31047.

5. Waltenberger J, Claesson-Welsh L, Siegbahn A, Shibuya $\mathrm{M}$, Heldin $\mathrm{CH}$. Different signal transduction properties of KDR and FIt1, two receptors for vascular endothelial growth factor. J Biol Chem 1994; 269: 26988-26995.

6. Shalaby F, Rossant J, Yamaguchi TP, Gertsenstein M, Wu protect against respiratory distress syndrome (12). We found that there is negative modulation in the evolution of the expression of VEGF receptors, and it is noted that as VEGFR1 tends to decrease during these stages, VEGFR2 tends to increase. This result is always more evident on $\mathrm{CDH}$ fetuses, as previously reported $(8,9)$.

This decrease in both receptors may be explained by the lung immaturity that results in $\mathrm{CDH}$ and also because of a toxic component of the herbicide that might interfere in the model, as both VEGF receptors decreased regardless of pulmonary hypoplasia being primary or secondary. Although a toxic component in the nitrofen group may exist, the $\mathrm{CDH}$ lungs had lower concentrations of VEGF receptors than all other groups. We believe that there is a synergy between increased VEGF and VEGFR1 and VEGFR2 in CDH, which may have clinical implications in compensating for the existing lung hypoplasia with $\mathrm{CDH}$.

Therefore, the decrease in VEGFR1 and VEGFR2 in the $\mathrm{CDH}$ rat model may suggest that these proteins are involved in the genesis of vascular growth and may correlate with pulmonary hypoplasia. This information may lead to new studies involving the mechanism of lung angiogenesis in $\mathrm{CDH}$ and possible treatment of pulmonary hypertension in the neonatal period.

\section{Acknowledgments}

Research supported by FAPESP (\#2008/50347-9, \#2011/00794-1, and Scholarships \#2008/52772-9 and \#2011/12587-0).

XF, Breitman ML, et al. Failure of blood-island formation and vasculogenesis in Flk-1-deficient mice. Nature 1995; 376: 62-66, doi: 10.1038/376062a0.

7. Shalaby F, Ho J, Stanford WL, Fischer KD, Schuh AC, Schwartz L, et al. A requirement for Flk1 in primitive and definitive hematopoiesis and vasculogenesis. Cell 1997; 89: 981-990, doi: 10.1016/S0092-8674(00)80283-4.

8. Kearney JB, Ambler CA, Monaco KA, Johnson N, Rapoport RG, Bautch VL. Vascular endothelial growth factor receptor Flt-1 negatively regulates developmental blood vessel formation by modulating endothelial cell division. Blood 2002; 99: 2397-2407, doi: 10.1182/blood.V99.7.2397.

9. Roberts DM, Kearney JB, Johnson JH, Rosenberg MP, Kumar R, Bautch VL. The vascular endothelial growth factor (VEGF) receptor Flt-1 (VEGFR-1) modulates Flk-1 (VEGFR2) signaling during blood vessel formation. Am J Pathol 2004; 164: 1531-1535, doi: 10.1016/S0002-9440(10)63711-X.

10. Fong GH, Rossant J, Gertsenstein M, Breitman ML. Role of the Flt-1 receptor tyrosine kinase in regulating the assembly of vascular endothelium. Nature 1995; 376: 66-70, doi: 10.1038/376066a0.

11. Okazaki T, Sharma HS, Aikawa M, Yamataka A, Nagai R, 
Miyano T, et al. Pulmonary expression of vascular endothelial growth factor and myosin isoforms in rats with congenital diaphragmatic hernia. J Pediatr Surg 1997; 32: 391-394, doi: 10.1016/S0022-3468(97)90588-1.

12. Compernolle V, Brusselmans K, Acker T, Hoet P, Tjwa M, Beck $\mathrm{H}$, et al. Loss of HIF-2alpha and inhibition of VEGF impair fetal lung maturation, whereas treatment with VEGF prevents fatal respiratory distress in premature mice. Nat Med 2002; 8: 702-710, doi: 10.1038/nm1102-1329b.

13. Oue $T$, Shima $H$, Taira $Y$, Puri P. Administration of antenatal glucocorticoids upregulates peptide growth factor gene expression in nitrofen-induced congenital diaphragmatic hernia in rats. J Pediatr Surg 2000; 35: 109-112, doi: 10.1016/S0022-3468(00)80025-1.

14. Chang R, Andreoli S, Ng YS, Truong T, Smith SR, Wilson J, et al. VEGF expression is downregulated in nitrofen-induced congenital diaphragmatic hernia. J Pediatr Surg 2004; 39: 825-828, doi: 10.1016/j.jpedsurg.2004.02.015.

15. Kluth $D$, Kangah $R$, Reich $P$, Tenbrinck $R$, Tibboel $D$, Lambrecht W. Nitrofen-induced diaphragmatic hernias in rats: an animal model. J Pediatr Surg 1990; 25: 850-854, doi: 10.1016/0022-3468(90)90190-K.

16. Scherle W. A simple method for volumetry of organs in quantitative stereology. Mikroskopie 1970; 26: 57-60.

17. Howard CV, Reed MG. Unbiased stereology. 1st edn. New York: Springer-Verlag New York Inc. in association with BIOS Scientific Publishers Ltd.; 1998.

18. Papadakis K, De Paepe ME, Tackett LD, Piasecki GJ, Luks FI. Temporary tracheal occlusion causes catch-up lung maturation in a fetal model of diaphragmatic hernia. $J$ Pediatr Surg 1998; 33: 1030-1037, doi: 10.1016/S00223468(98)90526-7.

19. Iritani I. Experimental study on embryogenesis of congenital diaphragmatic hernia. Anat Embryol 1984; 169: 133-139, doi: $10.1007 / B F 00303142$

20. Tenbrinck R, Tibboel D, Gaillard JL, Kluth D, Bos AP, Lachmann B, et al. Experimentally induced congenital diaphragmatic hernia in rats. J Pediatr Surg 1990; 25: 426-429, doi: 10.1016/0022-3468(90)90386-N.

21. Keijzer R, Puri P. Congenital diaphragmatic hernia. Semin Pediatr Surg 2010; 19: 180-185, doi: 10.1053/j.sempedsurg. 2010.03.001.

22. Alfanso LF, Arnaiz A, Alvarez FJ, Qi B, Diez-Pardo JA, Soler A, et al. Lung hypoplasia and surfactant system immaturity induced in the fetal rat by prenatal exposure to nitrofen. Biol Neonate 1996; 69: 94-100, doi: 10.1159/ 000244283.

23. Pringle KC. Human fetal lung development and related animal models. Clin Obstet Gynecol 1986; 29: 502-513, doi: 10.1097/00003081-198609000-00006.

24. Schmidt AF, Goncalves FL, Nassr AC, Pereira LA, Farmer $\mathrm{D}$, Sbragia L. Antenatal steroid and tracheal occlusion restore vascular endothelial growth factor receptors in congenital diaphragmatic hernia rat model. Am J Obstet Gynecol 2010; 203: 18-20, doi: 10.1016/j.ajog.2010.04.022.

25. Schmidt AF, Goncalves FL, Regis AC, Gallindo RM, Sbragia $L$. Prenatal retinoic acid improves lung vascularization and VEGF expression in CDH rat. Am J Obstet Gynecol 2012; 207: 76.e25-76.e32, doi: 10.1016/j.ajog.2012.04.025.

26. Leung DW, Cachianes G, Kuang WJ, Goeddel DV, Ferrara N. Vascular endothelial growth factor is a secreted angiogenic mitogen. Science 1989; 246: 1306-1309, doi: 10 1126/science.2479986.

27. Alon T, Hemo I, Itin A, Pe'er J, Stone J, Keshet E. Vascular endothelial growth factor acts as a survival factor for newly formed retinal vessels and has implications for retinopathy of prematurity. Nat Med 1995; 1: 1024-1028, doi: 10.1038/ nm1095-1024.

28. Larrivee B, Karsan A. Signaling pathways induced by vascular endothelial growth factor (review). Int $\mathrm{J} \mathrm{Mol} \mathrm{Med}$ 2000; 5: 447-456.

29. de Vries C, Escobedo JA, Ueno H, Houck K, Ferrara N, Williams LT. The fms-like tyrosine kinase, a receptor for vascular endothelial growth factor. Science 1992; 255: 989991, doi: 10.1126/science.1312256.

30. Quinn TP, Peters KG, de Vries C, Ferrara N, Williams LT. Fetal liver kinase 1 is a receptor for vascular endothelial growth factor and is selectively expressed in vascular endothelium. Proc Natl Acad Sci U S A 1993; 90: 75337537, doi: 10.1073/pnas.90.16.7533.

31. Hewett PW, Murray JC. Coexpression of flt-1, flt-4 and KDR in freshly isolated and cultured human endothelial cells. Biochem Biophys Res Commun 1996; 221: 697-702, doi: 10.1006/bbrc.1996.0659.

32. Jakkula M, Le Cras TD, Gebb S, Hirth KP, Tuder RM, Voelkel NF, et al. Inhibition of angiogenesis decreases alveolarization in the developing rat lung. Am J Physiol Lung Cell Mol Physiol 2000; 279: L600-L607.

33. Hislop AA. Airway and blood vessel interaction during lung development. J Anat 2002; 201: 325-334, doi: 10.1046/j. 1469-7580.2002.00097.x

34. Yamamoto $Y$, Shiraishi I, Dai P, Hamaoka K, Takamatsu T. Regulation of embryonic lung vascular development by vascular endothelial growth factor receptors, Flk-1 and Flt-1. Anat $\operatorname{Rec} 2007$; 290: 958-973, doi: 10.1002/ar.20564.

35. Tenbrinck R, Gaillard JL, Tibboel D, Kluth D, Lachmann B, Molenaar JC. Pulmonary vascular abnormalities in experimentally induced congenital diaphragmatic hernia in rats. J Pediatr Surg 1992; 27: 862-865, doi: 10.1016/0022-3468(92)90385-K.

36. Mata-Greenwood E, Meyrick B, Soifer SJ, Fineman JR, Black SM. Expression of VEGF and its receptors Flt-1 and Flk-1/KDR is altered in lambs with increased pulmonary blood flow and pulmonary hypertension. Am J Physiol Lung Cell Mol Physiol 2003; 285: L222-L231.

37. Shehata SM, Mooi WJ, Okazaki T, El-Banna I, Sharma HS, Tibboel D. Enhanced expression of vascular endothelial growth factor in lungs of newborn infants with congenital diaphragmatic hernia and pulmonary hypertension. Thorax 1999; 54: 427-431, doi: 10.1136/thx.54.5.427.

38. Oue T, Yoneda A, Shima H, Taira Y, Puri P. Increased vascular endothelial growth factor peptide and gene expression in hypoplastic lung in nitrofen induced congenital diaphragmatic hernia in rats. Pediatr Surg Int 2002; 18: 221226, doi: $10.1007 / \mathrm{s} 003830100625$.

39. Hara A, Chapin CJ, Ertsey R, Kitterman JA. Changes in fetal lung distension alter expression of vascular endothelial growth factor and its isoforms in developing rat lung. Pediatr Res 2005; 58: 30-37, doi: 10.1203/01.PDR.000016 3614.20031.C5

40. Robinson CJ, Stringer SE. The splice variants of vascular endothelial growth factor (VEGF) and their receptors. J Cell Sci 2001; 114: 853-865. 